\title{
Policy Research on Special Posts of National Rural Compulsory Education Teachers
}

\author{
Xiaoning Zhu ${ }^{1,2, *}$ Jiale $\operatorname{Han}^{1}$ \\ ${ }^{1}$ School of Public Affairs and Administration, University of Electronic Science and Technology of China, Cheng Du, Si \\ Chuan 611731, China \\ ${ }^{2}$ School of Public Affairs and Administration, University of Electronic Science and Technology of China, Cheng Du, Si \\ Chuan 611731, China \\ *Corresponding author. Email: Gina1995@126.com
}

\begin{abstract}
As a specific policy for supplementing rural compulsory education teachers in China, the Special Post Program involves multiple interest groups, and they play an important role in policy formulation and implementation. Based on the analysis model of interest groups, this paper analyzes the current policy status of the "Notice on the Implementation of the Special Plan for School Teachers in Rural Compulsory Education", and analyzes the policy from five perspectives: system, interest, policy participants, policy process and policy results. The analysis is helpful to understand the adjustment of the special post policy and understand how interest groups play their roles in the education policy.

Keywords: special post plan, interest group analysis model, education policy
\end{abstract}

\section{INTRODUCTION}

The national rural compulsory education teachers' special post policy is referred to as "special post plan", which is short for "rural compulsory education stage school teachers' special post plan". The policy was started in 2006, by the ministry of education, the ministry of finance, the former ministry of personnel, the central compilation office of the four departments jointly promulgated, after years of implementation, to promote urban and rural education equity, adjust the structure of rural school teachers, promote the employment of college students and other aspects played a positive role. In the new era, people's main contradiction has changed, and the current obstacles to the development of rural compulsory education is no longer the hardware equipment, software resources such as teachers occupy an increasingly important position. Therefore, as a policy to adjust the structure of rural teachers and improve the teaching level of rural teachers, the special post plan has been put in the forefront of research. The implementation of this policy involves multiple interest groups, including the central government, local governments, rural schools, special-post teachers, and students' parents. According to the core hypothesis of the analysis model of interest groups, public policy is the product of group struggle, and public policy mainly reflects the interests of the dominant group. Therefore, this paper holds that the policy formulation and implementation of the special post plan will be based on the consideration of their respective interest groups, which will ultimately affect the implementation effect and the actual effect of the policy.

At present, the research on interest groups of the special post plan mainly includes fan xiaodong's elaboration of the interests of the central government from the perspective of the inter-governmental political game [1] and the analysis of the contractual relationship between policy subjects [2]. Song lihua [3] studied the interest subjects in the special post policy from the perspective of definition of interests and multiple subjects. Gao xiaomin and sun tao [4] used interviews to investigate and study stakeholders. Tang yipeng et al. [5] made an empirical analysis of the benefits of special-post teachers from the research data of specialpost teachers. Wang min [6] used weber's tool perspective to analyze multiple principal value objectives of the special post plan. Their research has an enlightening and guiding effect on the follow-up research of the special post plan policy benefit group, and the research method is also of reference significance. This article is based on the related research, based on interest group policy analysis framework [7]involving the interests of different subjects, policy participants use the tools and methods and finally presents the effect of five aspects, identify each interest group in the education policy in the game, to deepen the interest groups influence on China's education policy, perfecting post to plan policy can play a positive effect.

\section{POLICY ANALYSIS}

Education is an interest field [8].Educational reform and policy making are about distribution and adjustment of various interest relations and interest patterns in education. It is the logical starting point to perfect the policy to analyze the interest relation in the special post plan policy. The analysis of this study is mainly carried out from five aspects: system analysis, benefit analysis, policy participant analysis, policy process analysis and policy result analysis. 


\subsection{System analysis}

The system analysis mainly analyzes the big political system and decision-making system of interest groups in the special post plan, which reflects the big stage of the current Chinese political society and determines the distribution of power among different state institutions. At the macro level, all power in the People's Republic of China belongs to the people. It is the people who, in accordance with legal procedures and on the basis of democratic elections, elect deputies to the people's congress and then form organs of state power, which produce other organs of state power, such as the state council and its subordinate organs. At the middle level, the special post plan is jointly issued by the ministry of education and other four departments. It not only has the relationship of business guidance to the education departments of provinces, cities and counties, but also has the relationship of authority and order compliance between superior and subordinate. From the micro level analysis, the special post policy is the four national ministries and commissions to further strengthen the construction of rural teachers, improve the quality of rural teachers guidance notice, issued documents to the relevant departments, did the work deployment and time requirements, so the introduction of the policy is a higher level to the lower level of guidance orders.

\subsection{Benefit analysis}

Interest analysis is to examine how to influence the behavior of interest groups from the perspective of interests. Interest is the main motive influencing the formulation and implementation of public policies. Sima qian once said that "all the people in the world are for profit and all the people in the world are for profit", so it is particularly important to analyze the interests of various interest groups.For the central government, the special post plan can solve the problem of weak teachers in rural areas, innovate the supplementary mechanism of rural teachers, narrow the gap between rural and urban education, and promote balanced development of education. At the same time, the special post policy has also expanded the employment channels for college and college graduates, and decomposed part of the domestic employment pressure, which is an active policy to kill two birds with one stone at the national level. For local governments, the special post plan is to introduce teachers to poor areas, which can bring in talents to these unappealing remote areas. In addition, the policy stipulates that the salary of special post teachers for three years is borne by the central finance, which can ease the pressure on local finance and improve the level of local compulsory education teachers. For local governments to raise the teachers helped, but according to the policy requirements, after 3 years the central subsidies, the teachers income after the establishment, its salary is borne by the local government, for its future fiscal spending is a pressure, therefore the local government for the policy will be more than the central government interests.In addition to the central and local governments, interest groups include groups of special-purpose teachers and the beneficiaries of special-purpose programs - students and families in poor areas. From the perspective of special post teachers to consider the interests, first of all, as rational "economic people", they tend to from the perspective of individuals, more consideration of salary, future career development prospects, personal social status, whether it is fair, whether they do more work and not get the corresponding monetary reward; Secondly, from the perspective of "social person", teachers in special posts have certain pursuit for harmonious colleague relationship, harmonious teacher-student relationship, as well as the understanding and support from parents and superiors for their work, which is a benefit consideration from the perspective of social relationship. Third in terms of "self-realization", some teachers not only think about their own vested interests, they also have a heart, want to realize own value by itself for the next generation to have a better development opportunity, we learned to national education, contribute our own strength, for them by education to realize their own value is also one of them to pursue interests; Finally, the group of special-post teachers is considered as "complex cultural people". In the context of Chinese culture, they also need to care about others' views on their career, their families' understanding of their work, as well as comprehensive considerations such as the hope that their children can receive better education. To sum up, for them, the special post plan is their choice of career, and they will take it into consideration in many aspects to maximize their own interests. The last interest group is students and families in rural areas. The policy can make them to accept to younger teacher, then they don't need to worry about spending money, so they generally considered for special interests for the plan of demand is positive, want to have a good teacher. And for them, getting a better education is an investment in their future.

In the consideration of interests, there is also a relationship of mutual relation and mutual restriction. For example, the central government gives three years' support in exchange for the local government's financial expenditure over many years for teachers recruited under the special post scheme. The teachers of special post are not satisfied with the economic benefits, which leads to the turnover of special post staff, which has an impact on the overall layout of the central government. The desire of rural children and families for the quality of education leads to the corresponding policy making. The interests of these interest groups are also interrelated and mutually restricted.

\subsection{Policy participant analysis}

The analysis of policy participants is to have an understanding of the decision-making center in the system and to have an understanding of the distance between the policy participants and the decision-making center in the interest groups. In 2006, the special post plan policy was originally formulated by four ministries and commissions to implement the spirit of the fifth plenary session of the 16th CPC central committee and promote the balanced development of compulsory education. The policy 
participants in different interest groups are four ministries at the national government level and four departments at the local government level, which can be understood as the policy decision-making center is mainly social elite groups. Second, we analyze the distance between the decisionmaking center of policy participants, and judge which group is closer to the core of policy making. From the perspective of weber's bureaucratic theory, this paper believes that the four ministries and commissions of the state are closer to the core of policy making. Compared with other interest groups, the four ministries and commissions of the central government have more say in the formulation of the content of the special post plan, and the policy text will more reflect the consideration of the interests of the state. Compared with the central government, the distance between local governments and policy makers is longer, their influence is less than that of the central government, and their consideration for their interests will be reduced. In addition, local governments in administrative organs, due to hierarchical reasons, choose to obey the distribution of relevant interests more. In addition to the analysis of the participants at all levels of government as a government policy, plan, hills, interest group net benefits of collective rural students and families, due to their personal capacity constraints, such as age and political status, not directly involved in the policy making process, but in the context of the socialist society, under the background of the people are masters of the country's political, the interests of the people's congress at all levels and government for their policy considerations should be more original starting point. Beyond the analysis of the three groups, interest groups, the final interest groups, namely teachers, at this time because they did not form a group in the policy decisions, so at the beginning of the policy did not play a role, but as the policy enforcement, special duty teachers gradually form interest groups, they also gradually to special requirements for the planning policies of involvement in policy process, so as to gradually make policy adjustments to tend to benefit from the direction of their content, group game kimono continuously in the interests of all parties to make the planning policies, hills, reaching a new equilibrium.

\subsection{Policy process analysis}

The analysis of policy process mainly examines how various interest groups use their means to make the policy develop towards the direction they want in the policy adjustment.

During the decades when the special post plan was implemented, various interest groups have produced the motive and specific means to influence the special post plan policy. For each interest group, let's first analyze the teachers of special post who are most obviously driven by economic interests. Search literature by keyword "special post plan" in CNKI database, found the description of the article is about the present situation of special teachers, the writer may be education institutions or the teachers group, through the vivid, detailed data and interviews, can cause social attention, at the same time, they can also be used by adopting the various social networking APP ,through Q\&A channel of responding to the current treatment, to enter the special post plan of next unriddling for teachers, through the use of a variety of means, make the people, the government noted its demand, Let policies be adjusted to take more account of their vested interests. In addition, teachers use means to influence the result of the policy, the local government as the executor of the teachers policy, often combined with local specific conditions, through to the execution of the policy to express their interests, such as literature research of local government for the central government has the practice of interest game, through the special teachers employment application, get more support of central finance and improve the standards of the local education. On the other hand, the relationship between the local government and teachers of special post is a bilateral contract. It is stipulated in the document that the corresponding establishment will be given after three years' assessment, and whether the assessment requirements meet the standards or not is the local government's choice for them. By this means, teachers of special post will act in the direction they expect and their purpose will be realized. Third, the central government level, as the policy writer in the special post plan, can specify teachers' own conditions and assessment requirements through explicit provisions in the text, as well as the conditions for local governments to obtain financial support from the central government, and use the threshold to influence other interest groups. Last interest groups for students and parents in rural areas, their interests based on the change of the current principal contradiction, from the previous is learning to the studious, can improve the quality of education requirements, so from their perspective, there is a better teacher resources, and the feedback through the people's congress, social media, such as special duty planning policy in 2015, in the notice to join a "strengthening body sound beauty, shortage of foreign language, such as information technology weak subject teachers supplement", which is reflected the policy to benefit the masses demand for full implementation of quality education.

\subsection{Analysis of policy results}

The analysis of policy results starts with the final policy results and investigates the effect of the means used by interest groups in the policy process.

Currently, the special post program has been implemented for more than a decade, and the influence of interest groups on the policy results through various means can also be observed. Firstly, from the perspective of the impact of rural students on the policy, we can see that the changes to the teacher structure mentioned in the previous section can be reflected, and their needs are expressed in the policy results. From the perspective of teachers of special post, the policy results are analyzed again, and the information communication through online media is also effective. Based on keywords "teachers" in the CNKI retrieval, nearly a third of the collected literature is about the special teachers complain of, at the same time they also as go-getters group, 
in ZHIHU,DOUBAN,WEIBO these social platform, let people know that their social status and economic income, also make their own social value in the public eye improved, the most obvious is the result of the rural teacher's wages. According to a document issued by the state council in 2019, the average salary level of teachers in compulsory education at county level should not be lower than that of local civil servants. Third from the angle to analyze government policies as a result, through the establishment of local government to control special teachers, let teachers on-thejob during performance positively, it is only through 3 years "evaluation period" local teaching task can become a member within the system, the teachers of contract constraint, was improved the teaching quality of local and fulfill the responsibilities of local government; Finally, the central government's macro means, such as the allocation of the number of local special post plan, the necessary conditions for teachers to apply for special post and the document provisions on the assessment items, have reached the selection of special post teachers and the support to the local poor areas, and finally responded to the expectations of the people.

\section{CONCLUSION}

The interests of education are universal and cannot be avoided in the educational policy, because the policy is the written expression after the game of multi-interests. Therefore, the research on education policy requires us to recognize and face up to the interests of various interest groups, recognize their means, and ultimately achieve the effect of making the policy evolve to a better and stronger direction through the research on interest groups.

At present, strengthening the construction of teachers in rural schools is the development focus of compulsory education in China, which still involves multiple interest groups, and the special post plan, as one of the supplementary policies for rural teachers, has a comprehensive effect on its research. Through the analysis of various interest groups, we come to the conclusion that for teachers' interest groups, they want to improve their own economic interests and social status. For the central government, its ultimate goal is to achieve the balance of educational resources and realize the integration of urban and rural education. For local governments, they are in the position of policy game. The next step is to use their own finance to support local public services and provide better compulsory education services. The ultimate goal of the game among the three interest groups is to make the pure benefit collective rural students in the special post plan generate more benefits and make them better developed.

\section{REFERENCES}

[1]Fan,X.(2017) Game and Compliance: In the implementation of the "Special Post Plan" policy, intergovernmental authority governance. Teacher Education Research,29:24-30.

[2]Fan,X.(2018) Research on Handover Interface and Contract Space in the Implementation of "Special Post Program" Policy.Education Development Research,12:8084.

[3]Song,Lh.(2015) Analysis on the Implementation of Special Post Policy from the Perspective of the Interest Demands of Multiple Subjects. Educational review,8:3-6.

[4]Gao,Qc.(2019) Conflicts of interest: how special post teachers move from mobility to stability - Interview research based on stakeholders. Theory and Practice of Education,39:41-45.

[5]Tang Yp.(2019) How to retain rural teachers-An empirical study based on survey data of special post teachers in $\mathrm{G}$ province.Education Research,4:134-143.

[6]Wang M.(2011) The Game of Interests: "Special Post Program" from a Rational Perspective. Modern education management, 1:83-85.

[7]Chen Ss(2013). Interest Group Policy: A Preliminary Analysis Framework. Nanjing Social Sciences,6:71-77.

[8]Zhou xh,Wang 1.(2006) On the Interest Orientation of Education Policy Making - Analysis Perspective of Interest Group Theory. Education Science,22:9-12 